\title{
Caspase- 9 mediates synaptic plasticity and memory deficits of Danish dementia knock-in mice: caspase-9 inhibition provides therapeutic protection
}

\author{
Robert Tamayev ${ }^{1 \dagger}$, Nsikan Akpan², Ottavio Arancio ${ }^{2,4}$, Carol M Troy ${ }^{2,3,4}$ and Luciano D'Adamio ${ }^{1 *+}$
}

\begin{abstract}
Background: Mutations in either A Precursor protein (APP) or genes that regulate APP processing, such as BRI2/ ITM2B and PSEN1/PSEN2, cause familial dementias. Although dementias due to APP/PSEN1/PSEN2 mutations are classified as familial Alzheimer disease (FAD) and those due to mutations in BRI2/ITM2B as British and Danish dementias (FBD, FDD), data suggest that these diseases have a common pathogenesis involving toxic APP metabolites. It was previously shown that FAD mutations in APP and PSENs promote activation of caspases leading to the hypothesis that aberrant caspase activation could participate in AD pathogenesis.

Results: Here, we tested whether a similar mechanism applies to the Danish BRI2/ITM2B mutation. We have

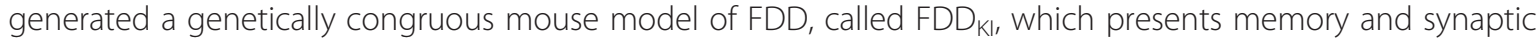
plasticity deficits. We found that caspase-9 is activated in hippocampal synaptic fractions of FDD KI $_{\text {mice }}$ and inhibition of caspase-9 activity rescues both synaptic plasticity and memory deficits.
\end{abstract}

Conclusion: These data directly implicate caspase-9 in the pathogenesis of Danish dementia and suggest that reducing caspase- 9 activity is a valid therapeutic approach to treating human dementias.

\section{Background}

The prevailing pathogenic model for dementias caused by mutations in APP and genes that regulate APP processing (PSEN1, PSEN2 and BRI2/ITM2b) posits that amyloid peptides trigger dementia. In $\mathrm{AD}$, the amyloid peptide is $A \beta$ that derives from APP processing. $\beta$ cleavage of APP, which is inhibited by BRI2, yields amino-terminal-soluble APP $\beta$ (sAPP $\beta$ ) and $\beta$-carboxylterminal fragments ( $\beta$-CTF). Processing of $\beta$-CTF by the $\gamma$-secretase complex, of which PSEN1 and PSEN2 constitute the catalytic components, releases $A \beta$. In FDD and FBD the amyloidogenic peptides, called ADan and ABri respectively, are generated from the mutant BRI2 proteins.

\footnotetext{
*Correspondence: luciano.dadamio@einstein.yu.edu

${ }^{\dagger}$ Equal contributors

'Department of Microbiology \& Immunology, Albert Einstein College of Medicine, Bronx, NY 10461, USA

Full list of author information is available at the end of the article
}

To model FDD we generated $\mathrm{FDD}_{\mathrm{KI}}$ mice that, like FDD patients [1], carry a wild type Bri2/Itm $2 b$ allele and a Danish mutated allele [2]. FDD ${ }_{\mathrm{KI}}$ mice develop progressive synaptic and memory deficits due to loss of BRI2 protein [3]. Owing to the loss of BRI2, processing of APP is increased in FDD $[4,5]$, and $\mathrm{SAPP} \beta / \beta-C T F$, but not $A \beta$, trigger memory and synaptic deficits of $F D D_{K I}$ mice $[4,6,7]$. These observations are consistent with the recent findings that $\beta$-processing of APP, but not $A \beta$, triggers pathological modifications associated with $\mathrm{AD}$ in human neurons derived from both familial and sporadic $\mathrm{AD}$ cases [8] and that a mutation in APP that reduces the BACE1 cleavage of APP protect elderly individual from sporadic AD and normal memory loss associated with ageing [9]. These similarities suggest that FDD shares common pathogenic mechanisms with FAD, involving synaptic-toxic APP metabolites distinct from $\mathrm{A} \beta$.

We and others have shown that FAD mutations in APP and PSENs could promote activation of caspases 
[10-14]. These observations suggested that activation of caspases could play a pathogenic role in $\mathrm{AD}$. In the ensuing years, a vast literature has linked $A \beta$ to caspase activation, especially caspase-3, but a functional link has not been proven [15]. However, other reports have indicated that APP metabolites derived either from $\mathrm{SAPP} \beta$ or the intracellular portion of $\beta-\mathrm{CTF}$, and distinct from $\mathrm{A} \beta$, also can promote activation of caspases [16-19]. Most caspases are mainly involved in the orchestration of the controlled demise of a cell after an apoptotic signal. These caspases are divided into those that initiate the apoptotic cascade (caspase-2, -8, -9 and -10, "initiator" caspases) and those that that execute apoptosis (caspase-3, -6, and -7, "effector" caspases). Initiator caspases are usually activated by dimerization, while effector caspases are activated by cleavage by initiator caspases [20]. Several recent observations show that apoptotic caspases also regulate other pathways including synaptic plasticity [21]. Based on these observations we tested whether caspases take part in the pathogenesis of memory loss and synaptic plasticity deficits of $\mathrm{FDD}_{\mathrm{KI}}$ mice.

\section{Results}

The caspase inhibitors Z-VAD-fmk and Z-LEHD-fmk, but not Z-DEVD-fmk, rescue the synaptic plasticity deficits of FDD ${ }_{\mathrm{KI}}$ mice

In 1928 Ramon y Cajal predicted that weakening of synapses leads to dementia. Long-term potentiation (LTP) is a synaptic plasticity phenomenon that underlies the strengthening of synaptic functions during memory acquisition. Consistent with Ramon y Cajal's prediction, LTP is defective in the hippocampal Schaffer collateral pathway of $\mathrm{FDD}_{\mathrm{KI}}$ mice. However, basal synaptic transmission and paired-pulse facilitation are normal in $F_{\mathrm{KI}}$ mice, suggesting that no changes in $\mathrm{Ca}^{2+}$ mobilization or alterations in the probability of neurotransmitter release are driven by the Danish mutation [3]. To examine the role of caspases in synaptic plasticity, we analyzed the effect of the cell-permeable, irreversible pan-caspase inhibitor Z-VAD-fmk on LTP. Hippocampal slices were perfused either with Z-VADfmk (at $10 \mu \mathrm{M}$ concentration) or vehicle for $60 \mathrm{~min}$ before inducing LTP. Z-VAD-fmk reversed the LTP deficit of Danish samples and did not alter LTP in wild-type mice (Figure 1).

Most caspases are expressed in the hippocampus. To start dissecting which caspase(s) play(s) a role in LTP deficits in $\mathrm{FDD}_{\mathrm{KI}}$ mice, we analyzed the effect of ZLEHD-fmk and Z-DEVD-fmk, which have partially overlapping inhibitory patterns of caspases inhibition. As shown in Figure 1, Z-LEHD-fmk behaved similarly to ZVAD-fmk (i.e. it fully rescued the LTP deficit of FDD KI mice, without imposing on normal synaptic plasticity). In contrast, LTP Z-DEVD-fmk delayed, but did not

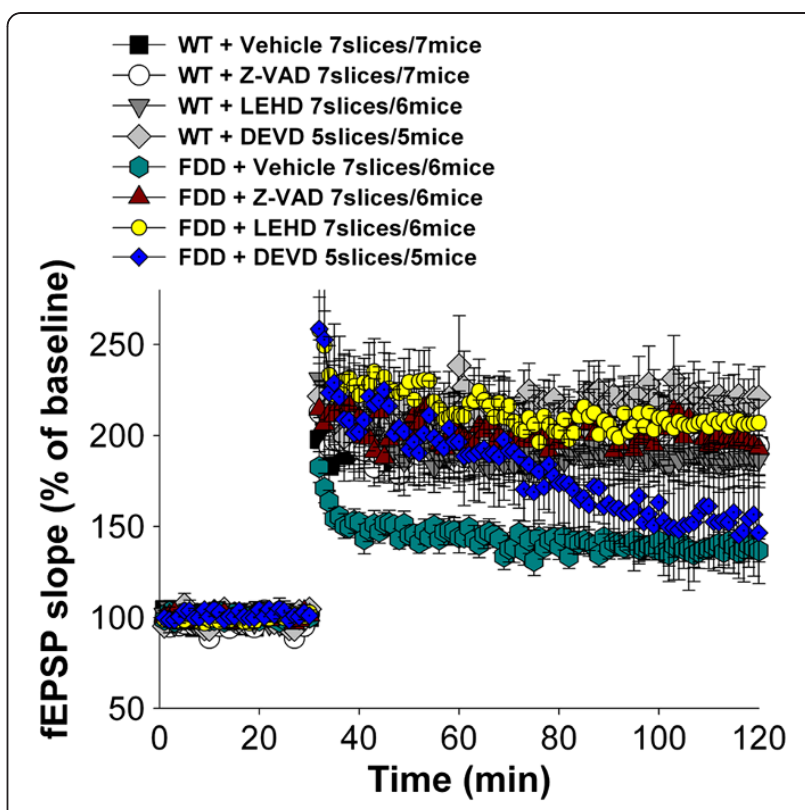

Figure 1 Z-VAD-fmk and Z-LEHD-fmk rescue the synaptic deficits of $\mathrm{FDD}_{\mathrm{KI}}$ mice. Vehicle-treated slices from $F D_{\mathrm{KI}}$ mice exhibited a reduction in LTP compared to slices from vehicle-treated WT littermates [WT/vehicle vs. FDD/vehicle: $F(1,12)=27.008, P<$ $0.0001]$. Perfusion with either $10 \mu \mathrm{M}$ Z-VAD-fmk or $2 \mu \mathrm{M}$ Z-LEHD-fmk

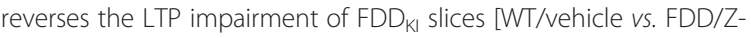
VAD-fmk: $F(1,12)=0.191, P=0.671$. FDD/vehicle vs. FDD/Z-VAD-fmk: $F(1,12)=14.300, P=0.003$. WT/vehicle vs. FDD/Z-LEHD-fmk: $F(1,12)=$ 34.592, $P<0.0001$. FDD/vehicle vs. FDD/Z-LEHD-fmk: $F(1,12)=34.592$, $\mathrm{P}<0.0001$ ] but did not alter normal LTP responses in WT mice [WT/ vehicle vs. WT/Z-VAD-fmk: $F(1,12)=0.032, P=0.861$. WT/vehicle vs. WT/ Z-LEHD-fmk: $F(1,12)=0.016, P=0.900]$. Differently, treating slices with $2 \mu \mathrm{M}$ Z-DEVD-fmk did not overall rescue synaptic plasticity deficits of $F D_{K I}$ mice [WT/vehicle vs. FDD/Z-DEVD-fmk: $F(1,12)=$ $0.191, P=0.671$. FDD/vehicle vs. FDD/Z-DEVD-fmk: $F(1,10)=4.272$; $\mathrm{P}=0.063]$, albeit it delayed the initiation of such deficits. In fact $Z$ DEVD-fmk rescued the LTP deficit during the initial 45 min of LTP [FDD/vehicle vs. FDD/Z-DEVD-fmk: $F(1,10)=8.93, P=0.012]$, but not the deficit occurring during the last $45 \mathrm{~min}$ of LTP [FDD/vehicle vs. FDD/Z-DEVD-fmk: $F(1,10)=1.23, P=0.29$ ]. Of note, Z-DEVD-fmk did not alter LTP in WT mice [WT/vehicle vs. WT/Z-DEVD-fmk: F F $(1,10)=$ $1.968, P=0.191]$. CA1-LTP was induced through a $\theta$ burst stimulation of the Shaffer collateral pathway.

rescue, the insurgence of LTP deficits in FDD $_{\mathrm{KI}}$ mice (Figure 1). The evidence indicates that some, but perhaps not any, caspases are involved in the pathogenesis of LTP deficits of FDD $\mathrm{KI}_{\mathrm{I}}$ mice.

The caspase inhibitor Z-LEHD-fmk, but not Z-DEVD-fmk, rescues the object recognition deficits of $F D D_{K I}$ mice

We reasoned that if caspases have a causative role in dementia, then inhibiting caspase activity should in addition rescue memory deficits of FDD $_{\mathrm{KI}}$ mice. To test for this, we analyzed the effect of Z-LEHD-fmk and ZDEVD-fmk on the memory deficits of FDD $\mathrm{KI}_{\mathrm{I}}$ mice in a longitudinal study. Memory was analyzed using novel object recognition (NOR), a non-aversive memory test 
that relies on the mouse's natural exploratory behavior. The first NOR study showed that during training, FDD ${ }_{\mathrm{KI}}$ and WT mice spent the same amount of time exploring two identical objects (Figure 2A, left panel), showing no discrimination between these two identical objects (Figure 2A, right panel). The following day, one of the two old objects was replaced with a new one to test the mouse's memory. WT mice preferentially explored the novel object; conversely $\mathrm{FDD}_{\mathrm{KI}}$ mice spent the same amount of time exploring the two objects as if they were both novel to them, showing that they had no memory of the objects from the previous day (Figure 2B, the left panel shows the time spent exploring each object, while the right panel show the discriminatory ratio). After this first test, the mice were rested for one day before re-testing. In this second experiment, the mice were injected in the lateral ventricle with $\mathrm{Z}$-LEHD-fmk $1 \mathrm{~h}$ before the training/testing trials. Treated $\mathrm{FDD}_{\mathrm{KI}}$ mice spent significantly more time exploring the novel object, just as treated controls did (Figure 2B). Following 2 days of rest, a new NOR test performed without treatments showed that $\mathrm{FDD}_{\mathrm{KI}}$ mice had relapsed into amnesia (Figure 2B), demonstrating that the therapeutic effect of Z-LEHD-fmk is short-lived. One day later, mice were injected $1 \mathrm{~h}$ before the training/ testing with Z-DEVD-fmk. Z-DEVD-fmk neither improved memory of $\mathrm{FDD}_{\mathrm{KI}}$ mice nor altered performance of WT animals (Figure 2B). Thus, Z-LEHD-fmk (which fully corrected the synaptic deficit of $\mathrm{FDD}_{\mathrm{KI}}$ mice) rescued, albeit temporarily, the memory deficit of $\mathrm{FDD}_{\mathrm{KI}}$ mice. In contrast, Z-DEVD-fmk (which, as show in Figure 1, was ineffi-

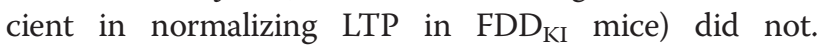
Although Z-LEHD-fmk and Z-DEVD-fmk are commonly referred to as specific caspase- 9 and caspase $3 / 7$ inhibitors, respectively, these compounds show overlapping selectivity [22]. Therefore from these experiments it is difficult to pinpoint the caspase(s) involved in these pathogenic processes. However, altogether these data suggest that one or more caspases mediate synaptic/ memory deficits of FDD $_{\mathrm{KI}}$ mice.

\section{The initiator caspase-9 is active in $\mathrm{FDD}_{\mathrm{KI}}$ mice hippocampal synaptic fractions}

Based on the evidence that caspases are pathogenic in $\mathrm{FDD}_{\mathrm{KI}}$ mice, we sought biochemical evidence of caspase activation and/or activity. Because FDD $_{\mathrm{KI}}$ mice have deficits in hippocampal-dependent memory and synaptic activity, which are associated with learning and memory, we tested whether we could detect signs of caspase activation in hippocampal synaptic preparations of 12 month-old mice. As discussed above, caspases are synthesized as zymogens (FL-caspase). Effector caspases are cleaved by initiator caspases (cl.-caspase) and this cleavage leads to activation of effector caspases. To allow unequivocal identification of active caspase we used an unbiased in vivo active caspase-trapping assay [23]. The caspase activity probe bVAD is the best way to determine whether caspases are active since bVAD binds irreversibly to all caspases that are active. In other words, if a caspase is active and its active site is available, bVAD will bind to it. Because bVAD is biotinylated, it can be isolated on streptavidin agarose along with any active caspase that is bound to it. This strategy has also the advantage of enriching for the apical active caspase rather than the downstream caspases in a pathway that involves a cascade of caspase activation. To determine which caspases are active, FDD $_{\mathrm{KI}}$ and WT mice were injected in one hippocampus with $100 \mathrm{nmol}$ of bVAD. In these experiments, we utilized 6 (Figure $3 \mathrm{~A}$ ) or 5 (Figure $3 \mathrm{~B}$ ) month-old mice since the memory deficits of FDD $_{\mathrm{KI}}$ mice start at around 4-5 months of age [3]. Two hrs post treatment, the injected region and the contralateral non-injected area were dissected, and bVADcaspase complexes were isolated on streptavidin-agarose beads and analyzed by Western blotting. bVAD captured greatly more FL-caspase-9, but not FL-caspase-8, from the hippocampus of the $\mathrm{FDD}_{\mathrm{KI}}$ sample as compared to the WT littermate sample (Figure 3A). The binding was specific because streptavidin-agarose beads did not pull-down active FL-caspase-9 from homogenates prepared from the contra-lateral, non-injected sample. Cl.caspase- 3 and -6 were not trapped by bVAD (Figure 3A). The inability to isolate cl.-caspase-3 and cl.-caspase- 6 may depend on the fact that bVAD inhibits caspase- 9 activity, thereby inhibiting processing of effector caspases- 3 and -6 by active caspase- 9 . This possibility is not very likely because in $\mathrm{FDD}_{\mathrm{KI}}$ mice there is probably ongoing caspase activation and bVAD will bind to any active caspase present at the moment of bVAD administration. Alternatively, cl.-caspase-3 may not be available for bVAD-binding because it is complexed in vivo with endogenous inhibitor of apoptosis proteins (IAPs). Lastly, cl.-caspase-3 and cl.-caspase-6 may be captured by bVAD at very low levels that are below the detection power of our experimental system. This is indeed a possibility given the low level of material that can be harvested in this experimental setting and the evidence that cl-caspase- 3 and cl-caspase- 6 are not detectable in the input material either.

To determine whether active caspase- 9 was present in synaptic fractions, we repeated the experiment and performed bVAD pull-downs from synaptosomal fractions. As shown in Figure 3B, active caspase-9 was also isolated from synaptosomal fractions of $\mathrm{FDD}_{\mathrm{KI}}$ but not WT mice. Blotting for caspase-3, -6 and -8 showed once more absence of detectable active caspase- $3,-6$ or -8 in these synaptosomal preparations (data not shown). To formally exclude that the differences between WT and FDD $_{\mathrm{KI}}$ mice illustrated above did not depend on 


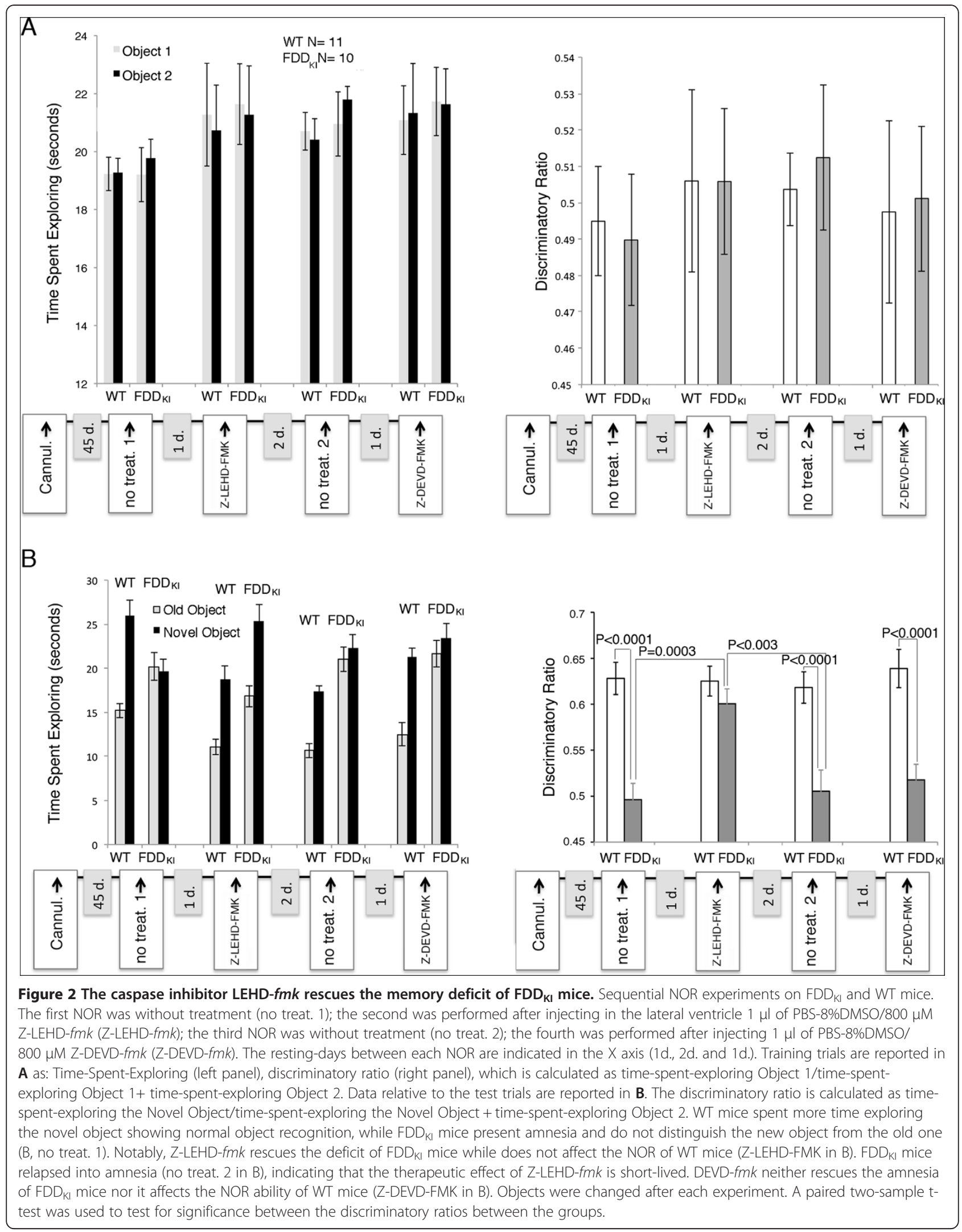




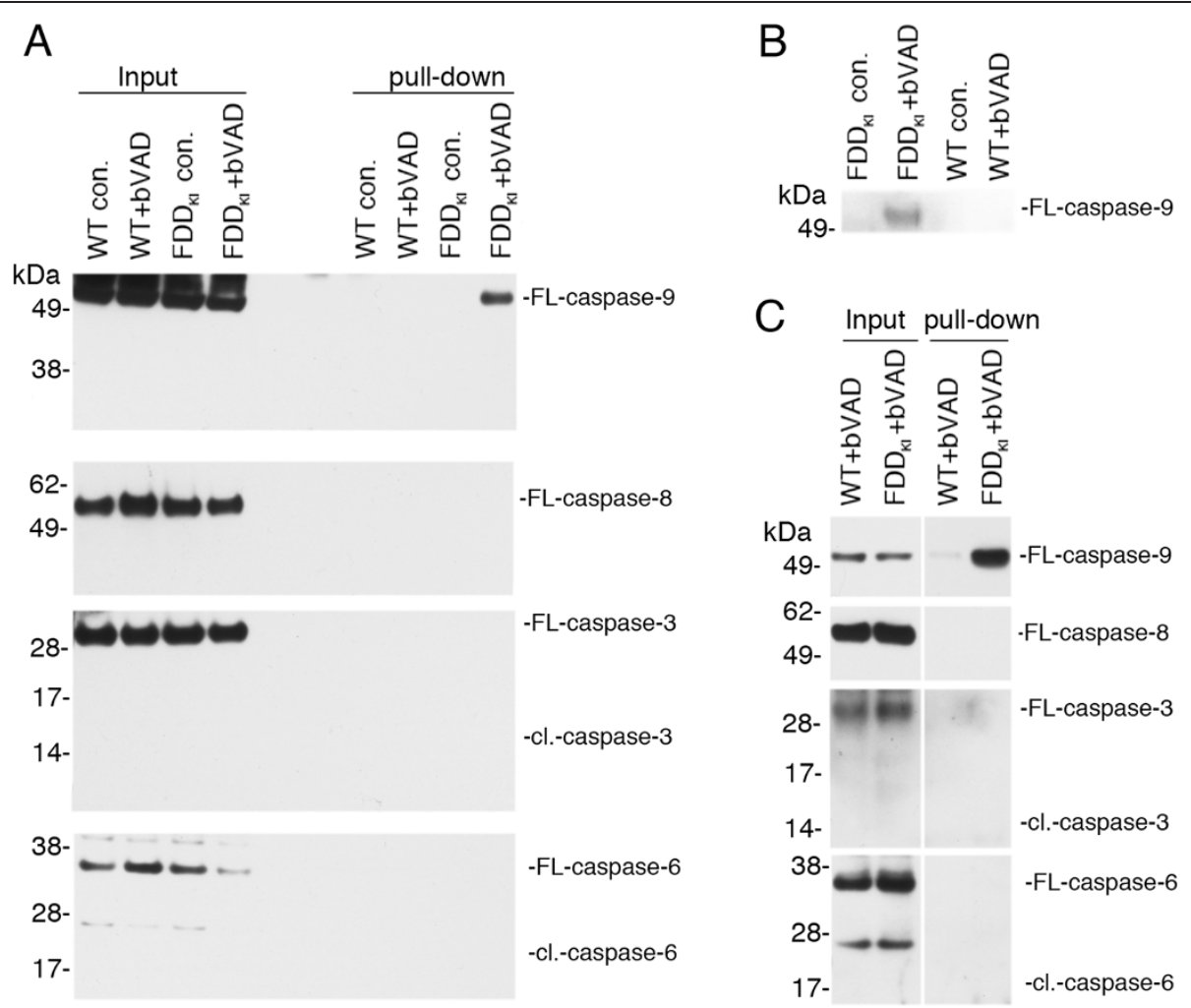

Figure 3 High levels of active initiator caspase-9 in FDD $_{\mathbf{K I}}$ mice. $\mathbf{A}$, Homogenates (input) were prepared from the bVAD injected (+bVAD) and contralateral non-injected (con.) hippocampal regions of $W T$ and $F D D_{K I}$ mice. Active caspases were isolated from homogenates with streptavidin-agarose-beads pull-down. Western blot analysis shows that the caspase inhibitor bVAD traps FL-caspase-9 only from the bVAD

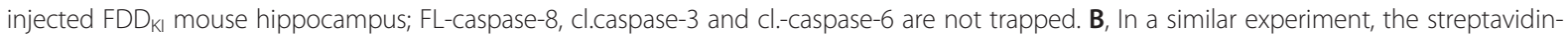
agarose-beads pull-down experiment was performed from the P2 fractions. The P2 fractions represent crude synaptosomal fractions (see Material

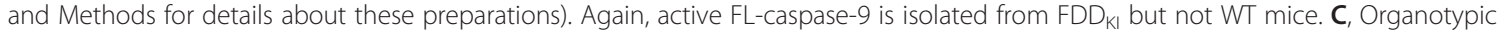
hippocampal cultures from either FDD $D_{\mathrm{KI}}$ or WT mice were incubated for 3 hrs with $45 \mu \mathrm{M}$ bVAD. After lysis, active caspases were isolated from homogenates. Again, caspase-9 was the only active caspase isolated. Albeit traces of active caspase- 9 are found in the WT samples, the levels found in the $F D D_{K I}$ hippocampus are greatly elevated. The blots shown in $A, B$ and $C$ are representative of duplicate experiments.

disparity of bVAD delivery in vivo, we prepared organotypic hippocampal cultures from 5 month-old WT and $\mathrm{FDD}_{\mathrm{KI}}$ mice. BVAD trapped significantly more active caspase-9 from organotypic hippocampal culture of $\mathrm{FDD}_{\mathrm{KI}}$ mice than WT littermates (Figure 3C). Once again, we could not detect active FL-caspase-8, cl.-caspase-3 and cl.-caspase- 6 neither in WT nor in FDD $_{\mathrm{KI}}$ sample. Altogether these data indicate that caspase- 9 is excessively activated in Danish dementia mice. Moreover, the data suggest that, if the Danish mutation triggers a cascade of caspase activation, caspase- 9 is the apical caspase in such a cascade.

\section{Specific inhibition of caspase-9 with Pen1-XBIR3 provides therapeutic rescue of the object recognition deficit}

The findings that reducing caspase activity with commercial peptide inhibitors rescues synaptic/memory deficits and that caspase- 9 is active in $\mathrm{FDD}_{\mathrm{KI}}$ mice, suggest that caspase- 9 is involved in the pathogenesis of these deficits. To specifically determine the functional relevance of caspase-9 activity in memory loss pathogenesis, we specifically inhibited caspase-9. As a control, we also used a specific inhibitor of caspase- 8 activity. Mammals express a family of cell death inhibiting proteins known as IAPs. IAPs contain BIR domains (יaculovirus Inhibitor of apoptosis protein Repeats), which perform specific functions. One member of this family, XIAP, is a potent specific inhibitor of active caspase- 9 , caspase- 3 , and caspase-7. The XIAP-BIR3 domain is a specific inhibitor of active caspase-9, and the XIAP-BIR2-linker domain inhibits active caspase- 3 and caspase-7 [24]. Serpins are also caspases inhibitors and CrmA (a cowpox serpin) inhibits caspase-8 (as well as caspase-1, which is involved in inflammatory responses) but not other murine caspases [25]. To provide intracellular delivery, XIAP-BIR3 and CrmA were disulfide-linked to Penetratin1 (Pen1), a cell-penetrating peptide [23]. Upon entry into the cell the reducing environment of the cytoplasm reduces the 

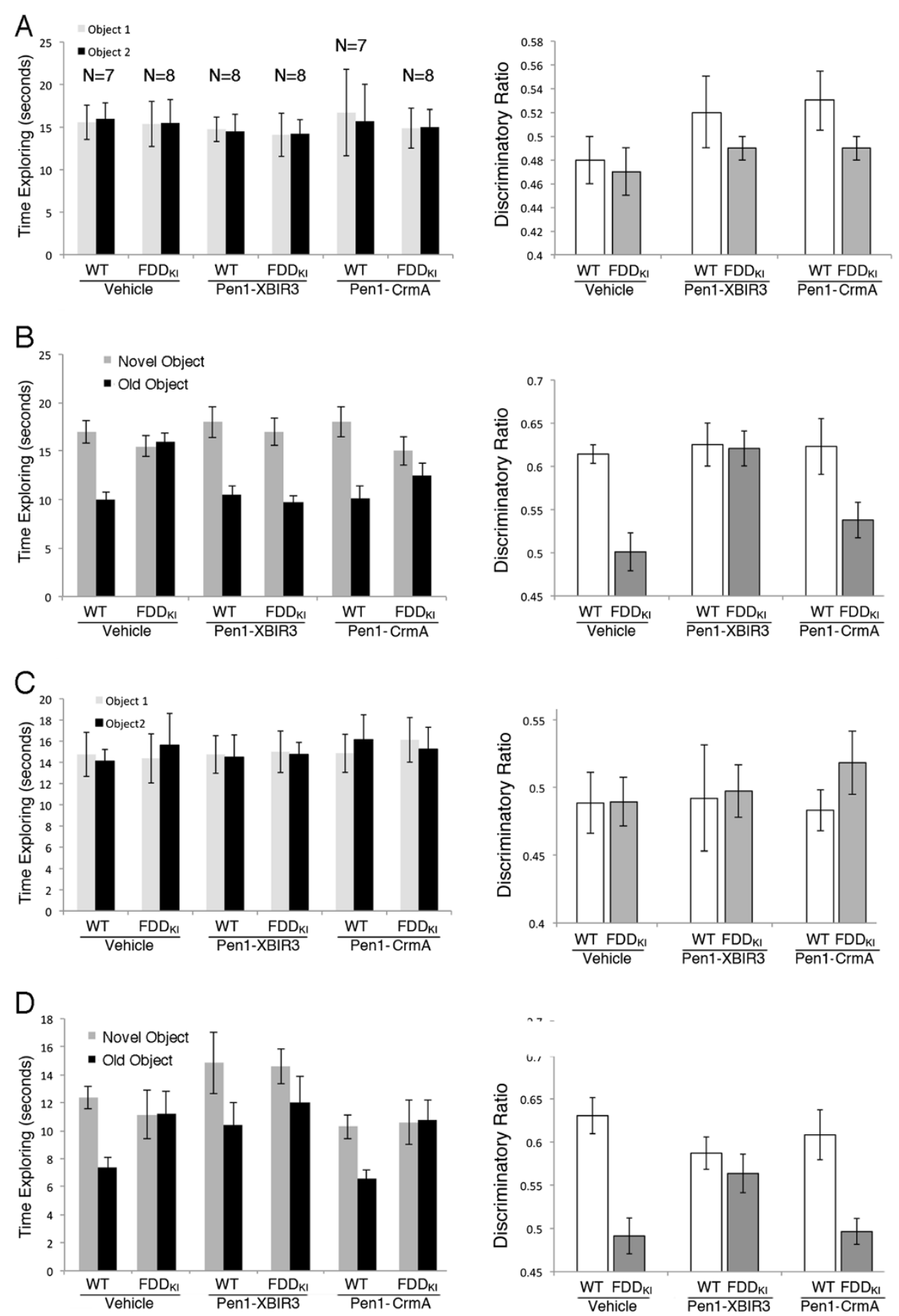

Figure 4 (See legend on next page.) 


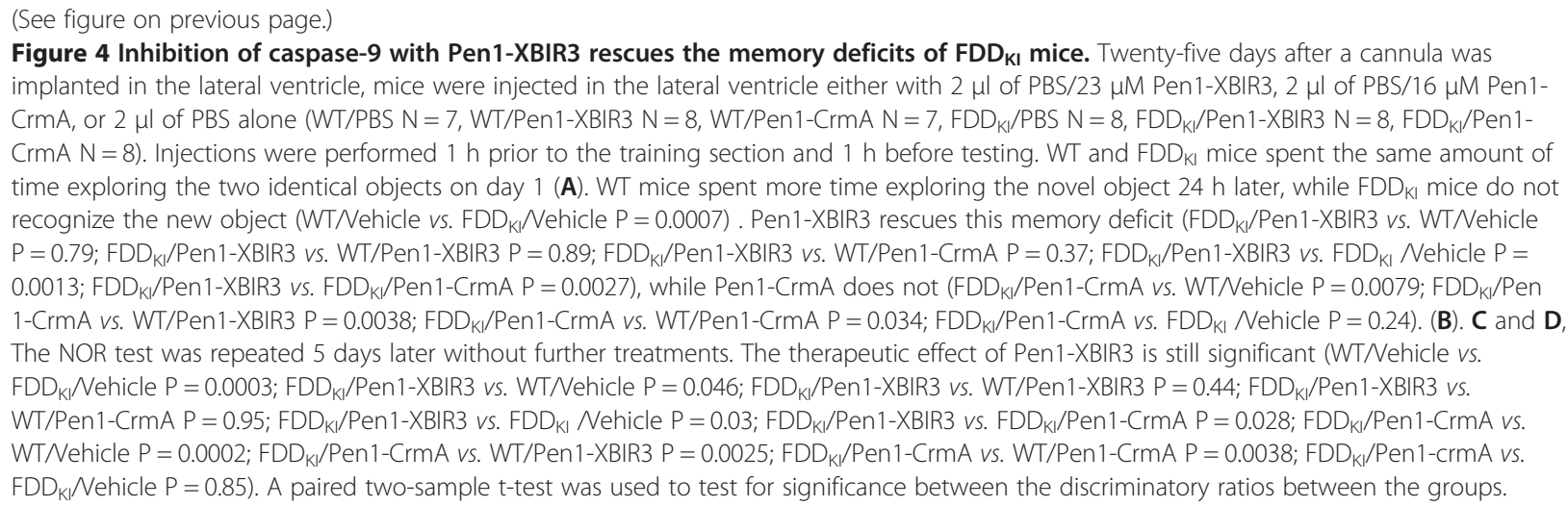

disulfide linkage. This releases the peptide cargo and allows it to act at its target. We have previously shown that Pen1-XBIR3 inhibits caspase-9 dependent cell death using primary hippocampal neuron cultures, and that Pen1-XBIR3 delivery to the CNS blocks caspase-9 in an in vivo model of cerebral ischemia [23]. NOR experiments were used to assess the effect of Pen1-XBIR3 on memory. Six groups of mice (3 groups of $\mathrm{FDD}_{\mathrm{KI}}$ mice and 3 groups of WT littermates) were injected in the lateral ventricle either with vehicle alone, Pen1-XBIR3 or Pen1-CrmA 1 hr before the training/testing trials. Pen1XBIR3 treated $\mathrm{FDD}_{\mathrm{KI}}$ mice spent significantly more time exploring the novel object showing reversal of the memory deficits (Figure 4A and B). On the contrary, Pen1CrmA treated FDD $_{\mathrm{KI}}$ mice showed memory deficits comparable to those observed in vehicle-treated FDD $_{\mathrm{KI}}$ mice. Neither Pen1-XBIR3 nor Pen1-CrmA altered memory in WT animals. Following 5 days of rest, a new NOR test performed without treatments showed that the therapeutic effect of Pen1-XBIR3 persisted for at least 5 days post injection (Figure $4 \mathrm{C}$ and D). Our previous studies showed that one dose of Pen1-XBIR3 provided functional protection against ischemia for 3 weeks post-infarction [23]. Thus, Pen1-XBIR3 rescued the memory deficit of FDD $_{\mathrm{KI}}$ mice, while Pen1-CrmA did not. These data indicate that excessive activation of caspase-9 in FDD $_{\mathrm{KI}}$ mice is an essential step in the pathogenesis of memory loss.

\section{Discussion}

We have tested whether caspases are involved in the pathogenesis of synaptic plasticity deficits and memory loss in $\mathrm{FDD}_{\mathrm{KI}}$ mice and have used an unbiased approach to identify caspases that are critical for these pathological processes. Our data show that caspase- 9 is a mediator of synaptic plasticity and memory deficits in FDD $_{\mathrm{KI}}$ mice. We have used active caspase trapping with bVAD, an irreversible pan-caspase inhibitor. This method provides a reliable measurement of caspase activity through biochemical pull-down of active caspases and has been shown to isolate active caspases-2, $-3,-7-8$, or -9 from cell lines [26], in primary neuron cultures [27] and in vivo in the CNS [23]. With this method we show that FDD $_{\mathrm{KI}}$ mice have high levels of active caspase- 9 in hippocampal synaptosomes. This is the first demonstration of a catalytically active initiator caspase in the hippocampus of animal models of familial dementia.

Inhibiting caspases with commercial peptide inhibitors reversed synaptic plasticity deficits and memory loss in FDD $_{\mathrm{KI}}$ mice. The beneficial effect on memory was shortlived and reversible. However, the commercial peptide inhibitors are promiscuous [22] and can lead to misinterpretation of data. Thus, we treated mice with highly specific inhibitors for caspase-8 (Pen1-CrmA) or caspase-9 (Pen1-XBIR3). Only Pen1-XBIR3 reversed memory deficits. The therapeutic effect remained significant even 5 days after treatment. Therefore, we conclude that active caspase- 9 plays an essential role in the pathogenesis of memory loss in $\mathrm{FDD}_{\mathrm{KI}}$ mice (Figure $5 \mathrm{~A}$ and B). Our previous findings showed that increased levels of APP metabolites derived by $\beta$-secretase processing of APP (sAPP $\beta$ and/or $\beta$-CTF) caused by loss of BRI2 protein in $\mathrm{FDD}_{\mathrm{KI}}$ mice are also responsible for synaptic/ memory deficits. The Danish mutation could alter APP processing and prompt caspase- 9 activation via independent mechanisms, starting two pathogenic pathways that are necessary but not sufficient to provoke the disease (Figure 5B). Alternatively, sAPP $\beta$ and/or $\beta$-CTF may prompt caspase- 9 activation, via a yet-to-be-defined pathway, activation of caspase-9. In turn, active caspase9 mediates downstream events, which are still uncharacterized and may involve other caspases, leading to synaptic and memory dysfunctions (Figure 5C).

Transgenic mice overexpressing human FAD mutant APP (Tg2576 mice) display an A $\beta$-dependent enhanced caspase- 3 activation, and Z-DEVD-fmk restores cognitive decline in $\operatorname{Tg} 2576$ mice [30]. It has also been shown that 

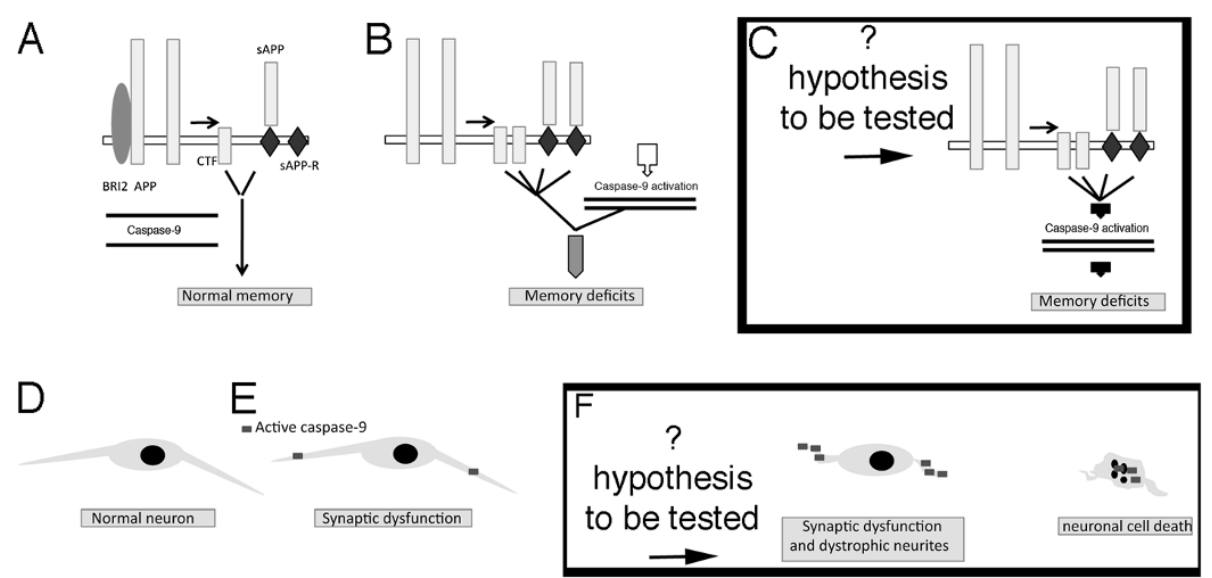

Figure 5 Hypothetical model depicting the mechanisms by which caspase- 9 can lead to alteration typical of neurodegenerative disorders: memory loss, dystrophic neurites and neuronal loss. A and $\mathbf{B}$, Previous work from our laboratory has shown that due to loss of BRI2 protein (loss of function model), APP processing is increased during synaptic transmission and memory acquisition in FDD leading to increased production of $S A P P \beta$ and $\beta-C T F$, leading to synaptic/memory deficits. We now show that caspase-9 is activated, via and unknown mechanisms, in FDD. This increased caspase-9 activation leads to synaptic/memory deficits via a yet to be defined mechanism. In $\mathbf{C}$, we postulate a hypothetical pathway in which caspase- 9 is activated by $\beta$-CTF and/or SAPP $\beta$, perhaps via interaction with a membrane-bound receptor, sAPP $\beta$ $\mathrm{R}$, such as DR6 [19]. Whether sAPPa and/or a-CTF can also trigger this pathway remains to be determined. In this context, it is worth noting that BRI2 also inhibits a-secretase processing of APP $[4,28,29]$. Further studies will be needed to assess the role of the a-processing pathway of APP in dementia. D and E, Aberrant activation of caspase-9 in synaptosomes causes functional impairments leading to synaptic plasticity and memory acquisition deficits, with no noticeable anatomical changes. In F, we hypothesize that repetitive cycles of high caspase-9 activity can lead to dystrophy of neurites. Prolonged and sustained activation of caspase-9 increases the probability that in any given neuron caspase- 9 activity may leak to the cell body and prompt the demise of the neuron.

XBIR2, but not XBIR3, rescues the hippocampal LTP deficits induced in vitro by synthetic A $\beta$ [31]. The BIR2 domain of XIAP inhibits active caspase-3 and caspase-7 [24]. Altogether, these results have lead to the conclusion that caspase-3, but not caspase-9, mediates the inhibition of LTP by synthetic $A \beta$. This is in contrast with the observations that only caspase- 9 is hyperactive in $\mathrm{FDD}_{\mathrm{KI}}$ mice and that memory deficits of $\mathrm{FDD}_{\mathrm{KI}}$ mice are rescued by ZLEHD-fmk and XBIR3 but not Z-DEVD-fmk. Those differences are consistent with the hypothesis that the deficits of $\mathrm{FDD}_{\mathrm{KI}}$ mice are $\mathrm{A} \beta$-independent. Based on these dissimilarities it could be argued that $\mathrm{FDD}_{\mathrm{KI}}$ and $\mathrm{Tg} 2576$ mice represent dementias caused by distinct pathogenic mechanisms, involving either sAPP $\beta / \beta-C T F$ and caspase9 or $A \beta$ and caspase- 3 , respectively. Alternatively, these mice may reproduce distinct stages of a common pathway leading to human dementia. It is also possible that either FDD $_{\mathrm{KI}}$ or Tg2576 mice develop synaptic/memory deficits that are triggered by artificial harmful effects unrelated to the pathogenesis of human dementias. In this regard, it is important to emphasize that the mouse model that we have analyzed, unlike transgenic mice, is genetically congruous to the human disease, suggesting that the mechanisms underlying synaptic and memory impairments in $\mathrm{FDD}_{\mathrm{KI}}$ mice faithfully reproduce the pathogenesis of human dementia.

When aberrant caspase-9 activation is confined to synaptic compartments, it leads to synaptic-memory deficits, as it is the case for $\mathrm{FDD}_{\mathrm{KI}}$ mice (Figure $5 \mathrm{D}$ and E). However, if activation of caspase- 9 is recurring and sustained, it may lead to dystrophy of neurites and to the demise of any given neuron in which active caspase9 leaks into the neuronal cell body triggering effector caspases and leading to genomic DNA fragmentation (Figure 5F). Over time, these changes can result in neuronal loss and neuritic dystrophy that are typical features of advanced neurodegenerative diseases.

Our study suggests that inhibiting caspase- 9 activity may be a viable therapeutic option in human dementias. Here, we have used intraventricular administration of Pen1-XBIR3 that provides direct delivery to the brain. In a previous paper we have shown that direct parenchymal or intranasal delivery of Pen1-XBIR3 is therapeutically effective in rat models of stroke [23]. From a therapeutic perspective, intranasal delivery is a very attractive treatment strategy for CNS disorders because it provides direct, noninvasive access to the brain via the olfactory pathway. Intranasal delivery combined with the cell-permeant peptide Pen1 makes Pen1-XBIR3 an attractive therapeutic compound for treatment of human dementias.

Ethical statement regarding the use and well fare of mice Mice were handled according to the Ethical Guidelines for Treatment of Laboratory Animals of Albert Einstein College of Medicine. The procedures were described and approved in animal protocol number 20100404. 


\section{Materials and methods \\ Mice}

$\mathrm{FDD}_{\mathrm{KI}}$, mice are on a C57BL/6 J background and were generated and maintained at the Animal facility of the Albert Einstein College of Medicine. Mice were handled according to the Ethical Guidelines for Treatment of Laboratory Animals of Albert Einstein College of Medicine. The procedures were described and approved in animal protocol number 200404.

\section{Electrophysiology}

Transverse hippocampal slices $(400 \mu \mathrm{m})$ from 1314 month old WT and FDD KI $_{\text {mice were transferred to a }}$ recording chamber where they were maintained at $29^{\circ} \mathrm{C}$ and perfused with artificial cerebrospinal fluid (ACSF) continuously bubbled with $95 \% \mathrm{O}_{2}$ and $5 \% \mathrm{CO}_{2}$. The ACSF composition in $\mathrm{mM}$ was: $124 \mathrm{NaCl}, 4.4 \mathrm{KCl}, 1$ $\mathrm{Na}_{2} \mathrm{HPO}_{4}, 25 \mathrm{NaHCO}_{3}, 2 \mathrm{CaCl}_{2}, 2 \mathrm{MgSO}_{4}$, and 10 glucose. CA1 field-excitatory-post-synaptic potentials (fEPSPs) were recorded by placing both the stimulating and the recording electrodes in CA1 stratum radiatum. After 90 minutes incubation, $10 \mu \mathrm{M}$ Z-VAD-fmk was added. For LTP experiments, a 30 min baseline was recorded every minute at an intensity that evoked a response approximately $35 \%$ of the maximum evoked response. LTP was induced using a $\theta$ burst stimulation (four pulses at $100 \mathrm{~Hz}$, with bursts repeated at $5 \mathrm{~Hz}$ and each tetanus including one ten-burst train). Responses were recorded for $90 \mathrm{~min}$ after tetanization and plotted as percentage of baseline fEPSP slope. ZVAD-fmk is from R\&D Systems.

\section{Brain cannulation and injections}

Dr. Xiaosong Li at the Animal Physiology core of the Albert Einstein College of Medicine surgically implanted the cannula. Using stereotaxic surgery performed under ketamine/xylazine anesthesia, mice were implanted with cannula (Plastics One Inc.) into the lateral ventricle (coordinates from bregma: A/P $-0.4 \mathrm{~mm}, \mathrm{M} / \mathrm{L}-1 \mathrm{~mm}$, $\mathrm{D} / \mathrm{V}-2.5 \mathrm{~mm}$ ) or hippocampus (coordinates from bregma: A/P -2.45 mm, M/L - $1.5 \mathrm{~mm}, \mathrm{D} / \mathrm{V}-1.7 \mathrm{~mm})$. Z-LEHD-fmk (800 nM), Z-DEVD-fmk (800 nM), or saline were delivered into the lateral ventricle at the rate of $1 \mu \mathrm{l}$ per minute using a CMA 400 syringe pump, for a total volume of $1 \mu \mathrm{l}$. Pen1-XBIR3 $(23 \mu \mathrm{M})$, Pen1-CrmA $(16 \mu \mathrm{M})$, or saline were delivered into the lateral ventricle at a rate of $1 \mu \mathrm{l}$ per minute using a CMA 400 syringe pump, for a total volume of $2 \mu \mathrm{l}$. Z-LEHD-fmk and Z-DEVD-fmk are from R\&D Systems.

\section{In vivo caspase activity assay}

Biotin-Val-Ala-Asp(OMe)-fluoromethylketone (bVAD; MP Biomedicals) was used as an in vivo molecular trap for active caspases. $5 \mu \mathrm{l}$ of bVAD (100 nmol) was injected into one hippocampus along with a blue dye using a CMA 400 syringe pump at a rate of $1 \mu \mathrm{l}$ per minute. Mice were sacrificed 2 hrs later, and the region with the blue dye was isolated from the rest of the hippocampus. The same region was collected on the contralateral hippocampus as the untreated/control. These regions were lysed separately in $10 \%$ glycerol, $150 \mathrm{nM} \mathrm{NaCl}, 0.2 \% \mathrm{NP}-40,20 \mathrm{mM}$ Tris-HCl ( $\mathrm{pH}$ 7.3) with protease and phosphatase inhibitors. For bVAD-caspase complex precipitation, protein lysates were precleared by rocking with Sepharose beads (GE Healthcare) for $1 \mathrm{~h}$ at $4^{\circ} \mathrm{C}$. Precleared lysate was centrifuged, and the supernatant was transferred to $30 \mu \mathrm{l}$ of streptavidinagarose beads (Sigma) and rocked gently overnight at $4^{\circ} \mathrm{C}$. Beads were washed/centrifuged (300 $\mu \mathrm{l}$ washes, $5000 \mathrm{rpm}$ for $1 \mathrm{~min}$ ) 15 times with bVAD lysis buffer. After the final wash/pelleting, caspase-bVAD complexes were boiled off of streptavidin beads into $1 \times$ SDS sample buffer without reducing agent. Beads were pelleted at $14,000 \mathrm{rpm}$ for $10 \mathrm{~min}$, and the supernatant was transferred to a fresh tube and resolved by SDS-PAGE.

\section{Organotypic hippocampal slices caspase activity assay}

Organotypic hippocampal slices were prepared and cultured as described previously [32]. Briefly, $400 \mu \mathrm{m}$ slices were prepared using a tissue chopper. Slices were transferred onto a cell culture insert that was placed into a 6-well plate in an incubator with $5 \% \mathrm{CO}_{2}$ and $78 \% \mathrm{O}_{2}$. The plate contained $1 \mathrm{ml}$ of culture media (MEM with Glutamax-1 supplemented with D-glucose, horse serum, nystatin, HEPES, EBSS, and Pen-Strep). The slices were cultured in the interface method. After $24 \mathrm{~h}$ of culture, the media was replaced with culture media containing $45 \mu \mathrm{M}$ bVAD for $3 \mathrm{~h}$ after which the slices were collected and lysed separately in $10 \%$ glycerol, 150nM NaCl, 0.2\% NP-40, 20 mM Tris-HCl (pH 7.3) with protease and phosphatase inhibitors. bVADcaspase complex precipitation was performed by preclearing with Sepharose beads and isolation with streptavidin-agarose beads as described in the preceding chapter. After the final wash/pelleting, caspasebVAD complexes were boiled off of streptavidin beads into $1 \times$ SDS sample buffer without reducing agent. Beads were pelleted at 14,000 rpm for $10 \mathrm{~min}$, and the supernatant was transferred to a fresh tube and resolved by SDS-PAGE.

\section{Open field and novel object recognition}

The mice were acclimated to the testing room for $30 \mathrm{~min}$ after being moved. Each mouse was placed into a $40 \mathrm{~cm} \times 40 \mathrm{~cm}$ open field chamber with opaque walls, $2 \mathrm{ft}$ high. Each mouse was allowed to habituate to the normal open field box for $10 \mathrm{~min}$, and repeated again $24 \mathrm{~h}$ later, in which we manually recorded the number of entries into and time spent in the center of the locomotor arena. As previously reported [3], open field 
studies showed that $\mathrm{FDD}_{\mathrm{KI}}$ mice have no defects in habituation, sedation, risk assessment and anxiety-like behavior in novel environments.

Novel object recognition began $24 \mathrm{~h}$ after the second open field session, and was performed as previously described [3,33]. Briefly, NOR consisted of two sessions $24 \mathrm{~h}$ apart. In the first session, the mice were placed into the open field chamber with two identical, non-toxic objects, $12 \mathrm{~cm}$ from the back and sidewalls of the open field box, and $16 \mathrm{~cm}$ apart from each other. An $8 \mathrm{~min}$ session, in which the time exploring each object was recorded; an area $2 \mathrm{~cm}^{2}$ surrounding the object is defined such that nose entries within $2 \mathrm{~cm}$ of the object were recorded as time exploring the object. We will refer to this as training trial. The animal was then returned to its home cage and $24 \mathrm{~h}$ late, placed into the open field box again. This time, there was one object identical to the previous one, and one novel object. We will refer to this as the test trial. The mice were given another $6 \mathrm{~min}$ to explore, and the amount of time exploring each object was recorded. Mice that spent $<7$ seconds exploring the objects were omitted from the analysis [33]. Results were recorded as Time Spent Exploring each object an object discrimination ratio (ODR), which is calculated by dividing the time the mice spent exploring object 1 (for the training trial) or the novel object (for the test trial) by the total amount of time exploring the two objects.

\section{Synaptosome preparation and Western blot analysis}

For synaptic preparations, isolated hippocampi were homogenized ( $\mathrm{w} / \mathrm{v}=10 \mathrm{mg}$ tissue/100 $\mathrm{ml}$ buffer) in Hepessucrose buffer (20 mM Hepes/ $\mathrm{NaOH}$ pH 7.4, $1 \mathrm{mM}$ EDTA, $1 \mathrm{mM}$ EGTA, $0.25 \mathrm{M}$ sucrose) supplemented with protease and phosphatase inhibitors. Homogenates were centrifuged at $800 \mathrm{~g}$ for $10 \mathrm{~min}$. The supernatant (S1) was separated into supernatant (S2) and pellet (P2) by spinning at 9,200 g for $15 \mathrm{~min}$. Synaptosome fractions represent: S1, post-nuclear-supernatant; S2, cytosol, soluble proteins and light membrane; P2, crude synaptosomal fraction. The S1 and P2 fractions were analyzed by western blot using the following antibodies: $\alpha$-caspase-3 (9662/Cell signaling); $\alpha$ caspase-6 (9762/Cell Signaling); $\alpha$-caspase-8 (4790/Cell Signaling); $\alpha$-caspase-9 (ab28131/Abcam. Secondary antibodies conjugated with horse-radish peroxidase are from Southern Biotechnology.

\section{Image scanning and analysis}

Western blot images were scanned with Epson Perfection 3200 Photo scanner and were analyzed with NIH ImageJ software.

\section{Statistical analysis}

All data are shown as mean \pm s.e.m. Statistical tests included two-way ANOVA for repeated measures and t- test when appropriate. All experiments were performed in a blinded fashion.

\section{Competing interests}

The $\mathrm{FDD}_{\mathrm{KI}}$ mice are patented by the Albert Einstein College of Medicine. LD is inventor of this patent.

\section{Authors' contributions}

LD generated the mice. RT performed behavioral and LTP experiments. LD performed hippocampal preparations, caspases activation tests and western blot analysis. LD designed research and wrote the paper. NA and CMT provided recombinant proteins. CMT participated in designing the caspase-activation experiments. OA provided the rig for electrophysiology and helped analyzing the LTP data. All authors read and approved the final manuscript.

\section{Acknowledgements}

We thank Dr. Guy S. Salvesen, for providing the XBIR3 recombinant protein. This work was supported by grants from the Alzheimer's Association (IIRG 09-129984 and ZEN-11-201425), the Edward N and Della L. Thome Memorial Foundation grant and the National Institutes of Health (NIH; AG033007, AG041577 and AG041531) to LD and (NIH; R01NS049442) to OA.

\section{Author details}

1Department of Microbiology \& Immunology, Albert Einstein College of Medicine, Bronx, NY 10461, USA. ²Departments of Pathology \& Cell Biology, Columbia University, New York, NY 10032, USA. ${ }^{3}$ Departments of Neurology, Columbia University, New York, NY 10032, USA. ${ }^{4}$ Departments of Taub Institute for the Study of Alzheimer's Disease and the Aging Brain, Columbia University, New York, NY 10032, USA.

Received: 15 October 2012 Accepted: 5 December 2012 Published: 10 December 2012

\section{References}

1. Vidal R, Revesz T, Rostagno A, Kim E, Holton JL, Bek T, Bojsen-Moller M, Braendgaard $\mathrm{H}$, Plant G, Ghiso J, et al: A decamer duplication in the 3 ' region of the BRI gene originates an amyloid peptide that is associated with dementia in a Danish kindred. Proc Natl Acad Sci USA 2000, 97:4920-4925.

2. Giliberto L, Matsuda S, Vidal R, D'Adamio L: Generation and Initial Characterization of FDD Knock In Mice. PLoS One 2009, 4:e7900.

3. Tamayev R, Matsuda S, Fa M, Arancio O, D'Adamio L: Danish dementia mice suggest that loss of function and not the amyloid cascade causes synaptic plasticity and memory deficits. Proc Natl Acad Sci USA 2010, 107:20822-20827.

4. Tamayev R, Matsuda S, Giliberto L, Arancio O, D'Adamio L: APP heterozygosity averts memory deficit in knockin mice expressing the Danish dementia BRI2 mutant. EMBO J 2011, 30:2501-2509.

5. Matsuda S, Tamayev R, D'Adamio L: Increased AbetaPP processing in familial Danish dementia patients. J Alzheimers Dis 2011, 27:385-391.

6. Tamayev R, Matsuda S, Arancio O, D'Adamio L: beta- but not gammasecretase proteolysis of APP causes synaptic and memory deficits in a mouse model of dementia. EMBO Mol Med 2012, 4:171-179.

7. Tamayev R, D'Adamio L: Inhibition of gamma-secretase worsens memory deficits in a genetically congruous mouse model of Danish dementia. Mol Neurodegener 2012, 7:19.

8. Israel MA, Yuan SH, Bardy C, Reyna SM, Mu Y, Herrera C, Hefferan MP, Van Gorp S, Nazor KL, Boscolo FS, et al: Probing sporadic and familial Alzheimer's disease using induced pluripotent stem cells. Nature 2012, 482:216-220.

9. Jonsson T, Atwal JK, Steinberg S, Snaedal J, Jonsson PV, Bjornsson S, Stefansson H, Sulem P, Gudbjartsson D, Maloney J, et al: A mutation in APP protects against Alzheimer's disease and age-related cognitive decline. Nature 2012, 488:96-99.

10. Vito $P$, Lacana E, D'Adamio L: Interfering with apoptosis: $\mathrm{Ca}(2+)$-binding protein ALG-2 and Alzheimer's disease gene ALG-3. Science 1996, 271:521-525

11. Vito P, Ghayur T, D'Adamio L: Generation of anti-apoptotic presenilin-2 polypeptides by alternative transcription, proteolysis, and caspase-3 cleavage. J Biol Chem 1997, 272:28315-28320.

12. Vito $P$, Wolozin B, Ganjei JK, Iwasaki K, Lacana E, D'Adamio L: Requirement of the familial Alzheimer's disease gene PS2 for apoptosis. Opposing effect of ALG-3. J Biol Chem 1996, 271:31025-31028.

13. Wolozin B, Iwasaki K, Vito P, Ganjei JK, Lacana E, Sunderland T, Zhao B, Kusiak JW, Wasco W, D'Adamio L: Participation of presenilin 2 in 
apoptosis: enhanced basal activity conferred by an Alzheimer mutation. Science 1996, 274:1710-1713.

14. Yamatsuji T, Matsui T, Okamoto T, Komatsuzaki K, Takeda S, Fukumoto H, Iwatsubo T, Suzuki N, Asami-Odaka A, Ireland S, et al: G protein-mediated neuronal DNA fragmentation induced by familial Alzheimer's diseaseassociated mutants of APP. Science 1996, 272:1349-1352.

15. Troy CM, Akpan N, Jean YY: Regulation of caspases in the nervous system implications for functions in health and disease. Prog Mol Biol Trans/ Sci 2011, 99:265-305.

16. Passer B, Pellegrini L, Russo C, Siegel RM, Lenardo MJ, Schettini G, Bachmann M, Tabaton M, D'Adamio L: Generation of an apoptotic intracellular peptide by gamma-secretase cleavage of Alzheimer's amyloid beta protein precursor. J Alzheimers Dis 2000, 2:289-301.

17. Lu DC, Rabizadeh S, Chandra S, Shayya RF, Ellerby LM, Ye X, Salvesen GS, Koo EH, Bredesen DE: A second cytotoxic proteolytic peptide derived from amyloid beta-protein precursor. Nat Med 2000, 6:397-404.

18. Madeira A, Pommet JM, Prochiantz A, Allinquant B: SET protein (TAF1 beta, I2PP2A) is involved in neuronal apoptosis induced by an amyloid precursor protein cytoplasmic subdomain. FASEB J 2005, 19:1905-1907.

19. Nikolaev A, McLaughlin T, O'Leary DD, Tessier-Lavigne M: APP binds DR6 to trigger axon pruning and neuron death via distinct caspases. Nature 2009, 457:981-989.

20. Pop C, Salvesen GS: Human caspases: activation, specificity, and regulation. J Biol Chem 2009, 284:21777-21781.

21. Li Z, Jo J, Jia JM, Lo SC, Whitcomb DJ, Jiao S, Cho K, Sheng M: Caspase-3 activation via mitochondria is required for long-term depression and AMPA receptor internalization. Cell 2010, 141:859-871.

22. McStay GP, Salvesen GS, Green DR: Overlapping cleavage motif selectivity of caspases: implications for analysis of apoptotic pathways. Cell Death Differ 2008, 15:322-331.

23. Akpan N, Serrano-Saiz E, Zacharia BE, Otten ML, Ducruet AF, Snipas SJ, Liu W, Velloza J, Cohen G, Sosunov SA, et al: Intranasal delivery of caspase-9 inhibitor reduces caspase-6-dependent axon/neuron loss and improves neurological function after stroke. J Neurosci 2011, 31:8894-8904.

24. Eckelman BP, Salvesen GS, Scott FL: Human inhibitor of apoptosis proteins: why XIAP is the black sheep of the family. EMBO Rep 2006, 7:988-994.

25. Garcia-Calvo M, Peterson EP, Leiting B, Ruel R, Nicholson DW, Thornberry NA: Inhibition of human caspases by peptide-based and macromolecular inhibitors. J Biol Chem 1998, 273:32608-32613.

26. Tu S, McStay GP, Boucher LM, Mak T, Beere HM, Green DR: In situ trapping of activated initiator caspases reveals a role for caspase-2 in heat shockinduced apoptosis. Nat Cell Biol 2006, 8:72-77.

27. Tizon B, Ribe EM, Mi W, Troy CM, Levy E: Cystatin C protects neuronal cells from amyloid-beta-induced toxicity. J Alzheimers Dis 2010, 19:885-894.

28. Matsuda S, Giliberto L, Matsuda Y, Davies P, McGowan E, Pickford F, Ghiso J, Frangione B, D'Adamio $L$ : The familial dementia BRI2 gene binds the Alzheimer gene amyloid-beta precursor protein and inhibits amyloidbeta production. J Biol Chem 2005, 280:28912-28916.

29. Matsuda S, Giliberto L, Matsuda Y, McGowan EM, D'Adamio L: BRI2 inhibits amyloid beta-peptide precursor protein processing by interfering with the docking of secretases to the substrate. J Neurosci 2008, 28:8668-8676.

30. D'Amelio M, Cavallucci V, Middei S, Marchetti C, Pacioni S, Ferri A, Diamantini A, De Zio D, Carrara P, Battistini L, et al: Caspase-3 triggers early synaptic dysfunction in a mouse model of Alzheimer's disease. Nat Neurosci 2010, 14:69-76.

31. Jo J, Whitcomb DJ, Olsen KM, Kerrigan TL, Lo SC, Bru-Mercier G, Dickinson B, Scullion S, Sheng M, Collingridge G, et al: Abeta(1-42) inhibition of LTP is mediated by a signaling pathway involving caspase-3, Akt1 and GSK3beta. Nat Neurosci 2011, 14:545-547.

32. De Simoni A, Yu LM: Preparation of organotypic hippocampal slice cultures: interface method. Nat Protoc 2006, 1:1439-1445.

33. Bevins RA, Besheer J: Object recognition in rats and mice: a one-trial non-matching-to-sample learning task to study 'recognition memory'. Nat Protoc 2006, 1:1306-1311.

doi:10.1186/1750-1326-7-60

Cite this article as: Tamayev et al: Caspase- 9 mediates synaptic plasticity and memory deficits of Danish dementia knock-in mice: caspase-9 inhibition provides therapeutic protection. Molecular Neurodegeneration 2012 7:60.

\section{Submit your next manuscript to BioMed Central and take full advantage of:}

- Convenient online submission

- Thorough peer review

- No space constraints or color figure charges

- Immediate publication on acceptance

- Inclusion in PubMed, CAS, Scopus and Google Scholar

- Research which is freely available for redistribution 